\title{
EL CAMBIO DE PARADIGMA EN EL CINE DE CÓMIC
}

\author{
Jorge DE PRADA ARÉVALO
}

(Unicómic)

\section{RESUMEN}

De cómo la industria del cómic está quedando como granja de ideas para las producciones cinematográficas. Desde las primeras adaptaciones, su imposibilidad técnica a la hora de ser trasladadas al cine, los cineastas que amaban el cómic hasta que las grandes editoriales de cómic quedan como reductos de donde extraer ideas para películas y otros medios audiovisuales. De la adaptación a la granja de ideas.

Palabras clave: Marvel, DC, cine, adaptación, granja de ideas.

Es de sobra conocido que el cine y el cómic guardan una estrecha relación: esta simbiosis casi natural fue evolucionando desde la creación del cine como medio comercial en 1895 con los hermanos Lumière, Edison, Charles Pathé y Georges Méliès hasta las primeras décadas del siglo XX cuando la industria se afianza y comienza a surgir una industria del cine más corporativa. Ya con los pioneros del séptimo arte, tenemos el cortometraje de apenas 45 segundos rodado por Louis Lumière L'arroseur arrosé (1895), que no solo tiene el honor de ser la primera producción cinematográfica como tal: se trata también de la primera película cómica, llegando a ser la primera vez que se paga a un actor, se usa un argumento, se crea un cartel publicitario y se cobra entrada al público. Es curiosamente una adaptación de una tira de prensa publicada en Francia por Hermann Vogel en L'assiette de beurre. Por supuesto, un año más tarde se produce otro hito importante: se inaugura la costumbre de realizar remakes volviendo a rodar otra versión del mismo argumento.

Fue en 1905 cuando Winsor McCay crea Little Nemo in Slumberland publicado en el New York Herald. Little Nemo bebe gráficamente de las películas de estudio que ya por aquel entonces empiezan a experimentar con el guion, el encuadre y el montaje. Las aventuras de Nemo superan con creces lo que se podía ver durante aquellos años en las salas del cine, debido a lo limitado de los recursos técnicos frente a la ilimitada imaginación y arte de su autor. Pronto la exitosa creación de McCay llega a otros formatos: postales, juegos, libros, ropa, una obra de Broadway y por supuesto una de las primeras adaptaciones al cine de una obra de cómic. 


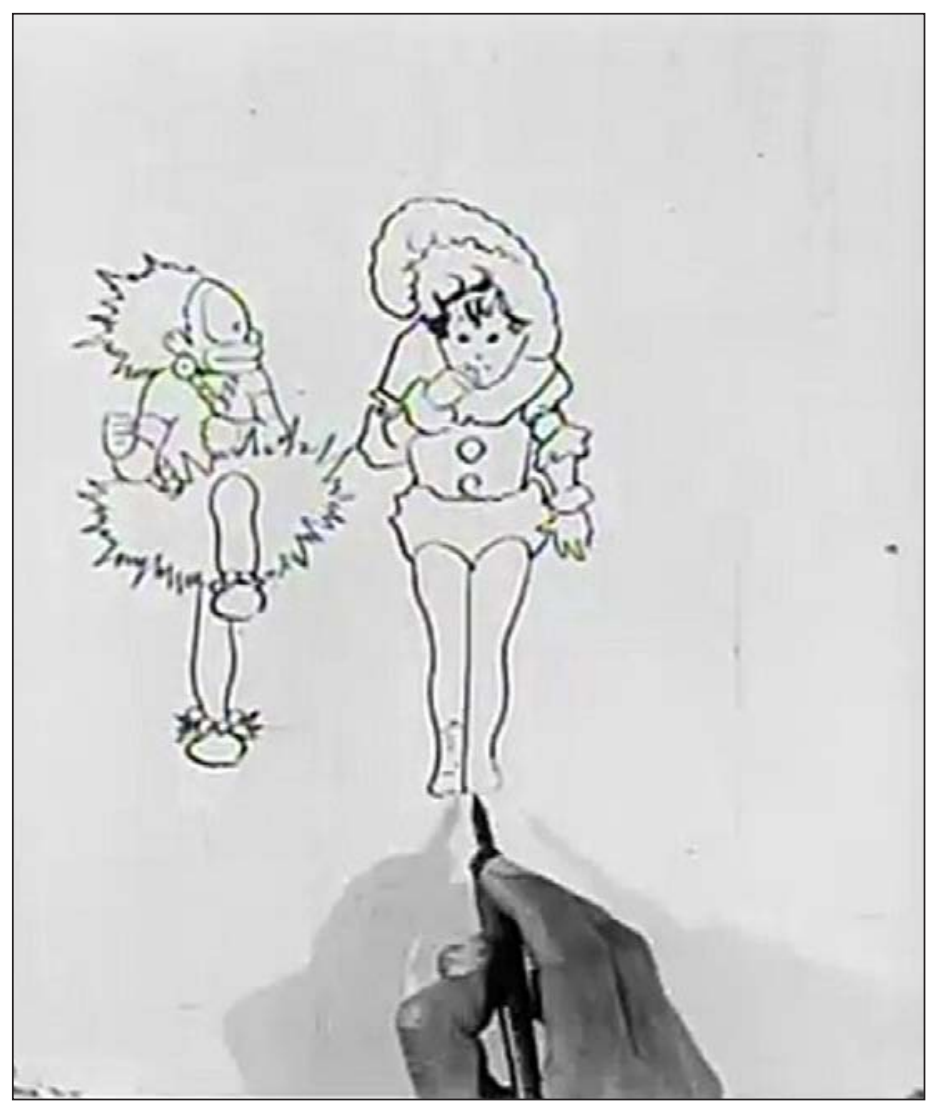

Fotograma de Little Nemo (1911)

Little Nemo (1911) es un pequeño corto de apenas minutos donde el protagonista es el propio Winsor McCay, que debe hacer en el plazo de un mes cuatro mil dibujos para producir un segmento animado; por supuesto este puede verse al final del corto. Estamos ante un primer encuentro entre el séptimo y el noveno arte; uno muy tímido, pero que muestra cómo ambas disciplinas se relacionaban y retroalimentaban.

No podemos olvidarnos de dos tempranas y prácticamente desconocidas adaptaciones que ya en la segunda década del siglo XX marcarían el modo en el que los grandes estudios se aproximarían al cómic. Hablo de Ella Cinders, película protagonizada por Colleen Moore que adapta las tiras cómicas del mismo nombre que tan solo con meses de diferencia se venían publicando en Cartoon \& Movies Magazine. Adaptación de una adaptación ya que el cómic original reimagina el cuento de Cenicienta en los años veinte con una estética propia de aquellos tiempos. Sus autores son Bill Conselman al guion y Charles Plumb a los lápices. Las primeras tiras cómicas de este personaje son trasladadas muy pronto, en lo que parece una estrategia de mercadotecnia al cine.

La otra es una adaptación de recorrido largo: primero en la cultura popular, luego al cine y finalmente al cómic en varias iteraciones en sentido contrario. Esto nos sirve una vez más para ilustrar esa estrecha relación entre los dos artes ya en sus primeros años de creación. Es Little Annie Rooney, personaje perteneciente al acervo cultural irlandés y al music hall que es protagonista de canciones, una película protagonizada por la legendaria Mary Pickford, una tira cómica propiedad de King Features y finalmente un corto animado de los estudios Fleischer, los mismos que adaptarían a serial cinematográfico las aventuras de Superman. 
El tropo de huerfanita da para mucho e incluso con la evolución del mismo veríamos nacer a otro personaje de papel: Little Orphan Annie. No es raro comprobar cómo el Hollywood de la época estaba dirigido por auténticos piratas que apenas respetaban el copyright favoreciendo las producciones derivadas sin ningún tipo de control, aunque si bien es cierto que fue a partir de los años veinte cuando los estudios empiezan a enrolar en sus filas a la figura del abogado que velaría por los intereses de las compañías y sus marcas.

Es imposible contemplar el éxito de Mickey Mouse o Félix el Gato sin tener en cuenta la larga tradición del género funny animals tan empleado en el cómic norteamericano. Obras como Krazy Kat de Hermann saltan de las tiras cómicas a la pantalla imitando el ejemplo de Little Nemo, mientras que Mickey o Félix son trasladados a su vez al cómic.

Llegados a este punto se hace necesario contextualizar algunos conceptos, como el de narrativa transmedia: acuñado en 1991 por la académica Marsha Kinder de la Universidad del Sur de California, aunque popularizado por Henry Jenkins en su obra Convergence Culture: La cultura de la convergencia de los medios de comunicación. Para Jenkins el transmedia es la suma de la estrategia de la industria y las tácticas de los usuarios o el resultado de la tensión entre el canon y el fandom. Son en resumen aquellas ficciones que trascienden su medio, por ejemplo del cine al cómic o del cómic al cine, creando un corpus narrativo complementario y permeable. La narrativa transmedia se nutre de las creaciones de autores que trabajan en un medio determinado, llamado nave nodriza por Jenkins. Salvo por Little Anne Rooney, vemos que en ejemplos anteriores el cómic constituye en principio esa nave nodriza de donde derivan las adaptaciones al cine; a partir de los años dos mil el concepto de nave nodriza en relación con el cómic y el cine quedaría cada vez más desdibujado.

Para ilustrar esta circunstancia, veamos varios ejemplos: las primeras adaptaciones de Batman trasladan casi al pie de la letra las tramas, los tropos y los detalles argumentales del cómic (en la serie de 1949 los nombres Bruce Wayne y Dick Grayson, los aliados Gordon y Vicky Vale; y en la adaptación de Tim Burton repiten Vicky Vale, Gordon y el villano Joker). Es cierto que en ocasiones se salen del canon oficial quedando así como nave nodriza principal el cómic. Pero sin embargo son cada vez más las películas y productos en principio derivados que sirven como fuente principal en sentido contrario: del cine al cómic. Personajes como Harley Quinn o René Montoya (ambas creadas en 1992 para la serie animada de Batman) han saltado de la televisión al cómic primero y finalmente al cine: Aves de Presa y la fantabulosa emancipación de Harley Quinn (2020), donde además reinventan por completo personajes como la propia René, la Cazadora o en un sentido muy radical a Cassandra Cain, que prácticamente es un personaje distinto a su homóloga en cómic. No menos importante es cómo diseños de conceptos como Blade, Guardianes de la Galaxia u otros cambian drásticamente al ver la editorial que lo representado en cine funciona para el público moderno.

Vemos que en las primeras tres décadas de cine y cómic esta interrelación se basa en tímidas adaptaciones a menudo para público infantil y siempre de forma independiente unas de otras. Pero cierto inmigrante llegaría al mundo del cómic para cambiarlo para siempre.

Creado por dos chavales aficionados a la ciencia ficción (un género del que beben en sus inicios la casi totalidad de los primeros superhéroes), Superman pone patas arriba muchas convenciones de los tebeos y a base de superfuerza cambia la percepción que tiene el público de estos.

La influencia de los tebeos de superhéroes en el cine es patente hoy en día, pero antes de los grandes blockbusters basados en cómics su relación era más asimétrica, siendo los 

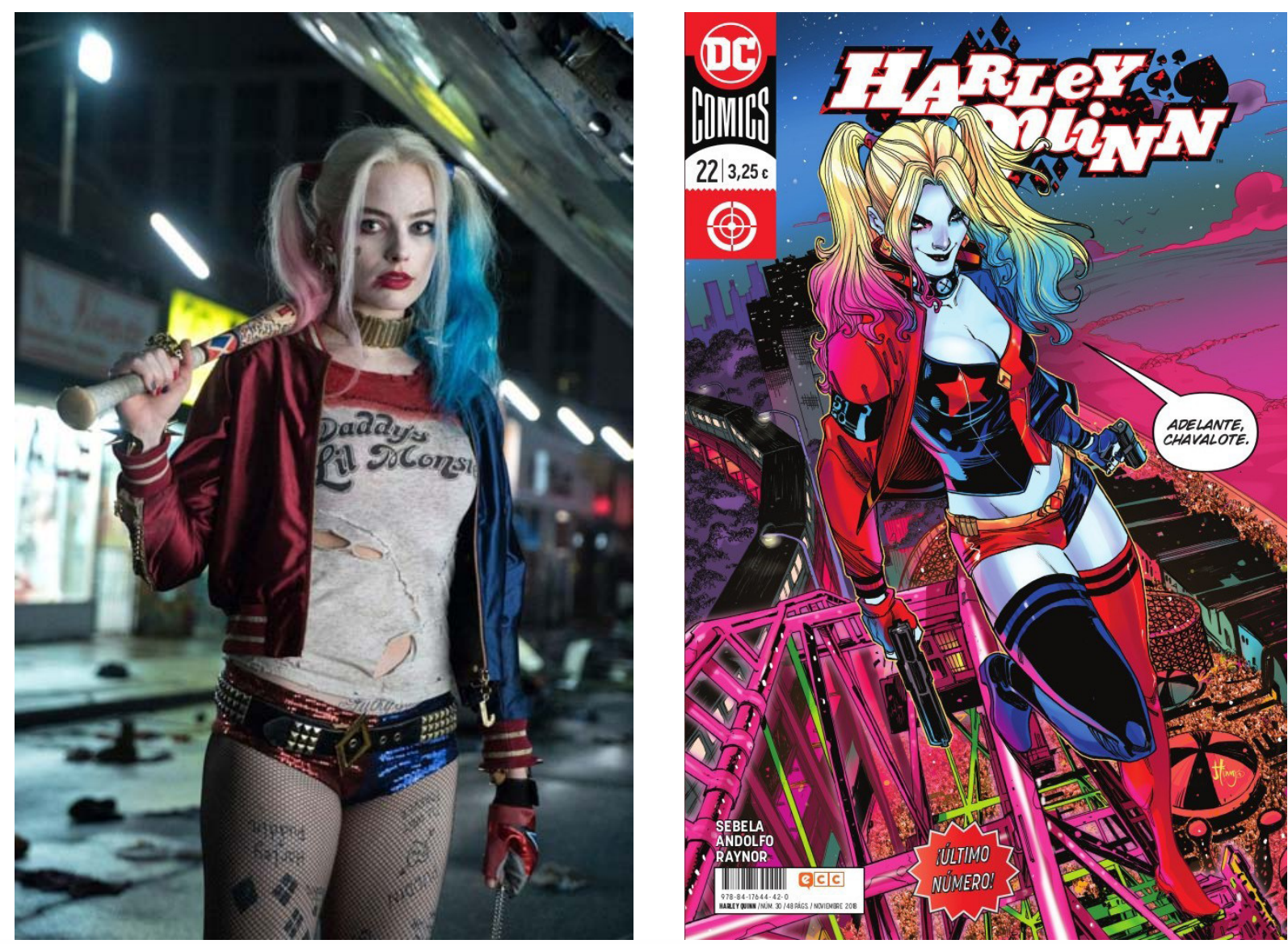

Comparativa de Harley Quinn interpretada por Margot Robbie y la versión actual del personaje

cómics quienes se inspiraban en el cine. No estamos hablando de adaptaciones sino de inspiración.

El comic book norteamericano tiene sus raíces muy hundidas en la literatura pulp de la época. Editoriales como National Comics (más adelante DC) o Timely Comics (Marvel) publicaban paralelamente esta clase de historias. Pero por supuesto el medio, ya maduro, no temblaba a la hora de coger prestados clichés o aspectos de otras historias, las cuales habían sido popularizadas por el cine. Ejemplos los tenemos en Superman, que bebe tanto de la tradición judía (Moisés, el Golem, etcétera) como de ficciones literarias al estilo de John Carter, de las cuales existen adaptaciones cinematográficas en aquella época. En la misma editorial tenemos a Batman, un personaje creado por Bob Kane y Jerry Finger -aunque Kane durante muchos años se atribuyó tramposamente la autoría total del cruzado enmascarado, finalmente se ha logrado reivindicar la autoría de Finger-. Batman es una amalgama producida por la suma de estos dos y de otros creativos: aunque es harto complicado saber con certeza quién aportó más al personaje, bien es cierto que existen declaraciones de cuál fue la aportación de cada uno. Kane declara que la inspiración le vino de un diseño de planeador de Leonardo da Vinci, además de las películas La marca del Zorro y The Bat Whispers. Para citar un último ejemplo citaremos un personaje cuyo potencial a la hora de generar historias variadas empieza a descubrirse ahora: el Joker. Para la creación de este villano sus creadores Kane, Finger y Robinson se basaron en el actor Conrad Veidt caracterizado como Gwynplaine en la película de 1928 El hombre que ríe. Vemos que el cómic, visto como el cine de los pobres, aún se inspiraba en el cine a la hora de crear 
historias y personajes. Pero bien es cierto que el medio al igual que la literatura era prolijo en ideas originales, algunas de las cuales eran difíciles de llevar a la pantalla de cine por las dificultades técnicas. Estamos en 1940 y la forma en la que el cine y el cómic se relacionaban estaba a punto de cambiar.

De este boom de los superhéroes nace una industria que hoy en día produce miles de dólares en ganancias gracias tanto al propio medio impreso como a una infinidad de productos derivados. Todo esto empieza con Superman. Entre 1930 y 1950 coincidiendo con las proyecciones en cine de los Saturday serials se ruedan al menos siete producciones basadas en creaciones de Marvel, DC, Fawcett y otros, aunque el auge de la televisión y la infantilización del medio que ya veía venir a Fredric Wertham y sus consecuencias acabarían con estas producciones. Durante veinte largos años los superhéroes son relegados al absurdo más infantil en la caja tonta y en papel.

Fue en 1967 cuando vuelve a producirse otro cambio sustancial. Sin olvidarnos de que pronto en los emergentes años setenta surgirían nuevos talentos en el mundo del cine que habían crecido leyendo cómics tanto de superhéroes como de terror, de crimen e incluso el underground. Esta circunstancia se iba a ver reflejada en los siguientes veinte años.

El conglomerado que hoy en día produce y gestiona las marcas intelectuales de DC comienza a formarse a finales de los años sesenta. La empresa inmobiliaria Kinney Parking Company va expandiendo su actividad a otros negocios (como una agencia de talentos, alquiler de coches, construcción, funeraria) y, finalmente, en 1967 adquiere el estudio Warner Bros, por aquella época en bancarrota. Antes de comprar un estudio de cine adquiere otra chuchería con la que jugar: DC.

Durante los setenta comienza a hablarse de una adaptación de gran presupuesto de Superman. DC experimenta un crecimiento amparado por la reciente fusión de todos los activos del entretenimiento de Kinney, que es renombrada y convertida finalmente en Warner Communications Inc. DC queda bajo el paraguas de Warner y es a día de hoy el único estudio que manufactura sus adaptaciones.

No nos olvidamos de Marvel, que desde 1963 revoluciona el mundo del tebeo con productos que uno de sus principales adalides (sin olvidarnos de Jack Kirby o Steve Ditko), Stan Lee, pretende llevar a la pantalla: así comienza un largo peregrinaje de cincuenta años hasta ver sus obras adaptadas fielmente. Este camino le daría más de un éxito, pero a la vez muchos disgustos, ya que para la época adaptar las atrevidas propuestas formales y argumentales de sus obras era muy costoso, siendo los resultados pobres comparados con sus versiones en papel impreso en cuatricromía. La imaginativa creatividad tanto de Lee como de Ditko, y no digamos ya de Kirby, resulta complicada de adaptar en lo que respecta a los efectos especiales.

Mientras DC contaba con un gran estudio que lo respaldaba, Marvel tenía a Stan Lee, un escritor y guionista de cine frustrado que amaba al cómic y lo defendía ante productores que no acababan de entender y comprar sus ideas. Salvo excepciones en televisión, las oscuras y pobres adaptaciones no reflejaban ni el potencial de sus personajes ni eran fieles a sus obras, cambiando a menudo y por capricho detalles como nombres o el propio trasfondo original. La imaginación de Stan Lee, todo un hombre de empresa con una enorme visión de negocio, le hacía crear personajes como She Hulk para evitar que la CBS, que por aquel entonces emitía Hulk, creara una versión femenina del mismo, con lo que no podría poseer los derechos del personaje; o defender a capa y espada a uno de sus personajes favoritos, Ant Man, ante los productores de New World Pictures que no veían el potencial 
al personaje... Con los años y el equipo adecuado ha resultado ser uno de los personajes más rentables.

El éxito de Superman vendría a cambiar la percepción de las adaptaciones de superhéroes. Siendo una película de gran presupuesto, Richard Donner demuestra que se puede ser más o menos fiel a la obra original. Para muchos de nuestra generación Christopher Reeve encarna a la percepción al visitante de Krypton. Esto animará a otros cineastas a emprender proyectos basados o inspirados en tebeos. A lo largo del mundo comienzan a surgir adaptaciones cinematográficas, sobre todo en animación con alguna ocasional incursión en el cine live action.

Los ochenta pertenecen a DC en cuanto a éxito de taquilla aun y todo con pocas producciones (saga de Superman y Batman), yendo a la zaga Marvel con mayor dificultad para producir un film de alto presupuesto. Se ha dicho ya que por esta época muchos cineastas debían parte de su bagaje cultural al mundo del cómic. Algunos de los citados son Steven Spielberg, Martin Scorsese, George A. Romero o George Lucas. Es curioso y parece demostrar la importancia del cómic sobre el cine que en esta época hay producciones de clara inspiración comiquera como la dupla Creepshow, que rinde homenaje a la editorial EC y su Tales from the Crypt; o Condorman, una película de la factoría Disney. Estas tres películas no adaptan personajes o cómics concretos sino más bien formas de narrar y tropos que habían nacido entre viñetas.

El creador de Star Wars bebe de muchas fuentes de inspiración a la hora de crear mundos ficticios. Por supuesto, el creador de La guerra de las galaxias es un confeso lector de tebeos: aunque no está probado, se dice que parte de la imaginería de Star Wars está prestada de Valerian, cómic francés publicado años antes que la saga galáctica. Otra de las incursiones de Lucas en el tebeo la tenemos en la fallida Howard, un nuevo héroe, película que no se reivindica lo suficiente y que es un fallido esfuerzo por adaptar un cómic demasiado brillante para el cine. El material creado por Steve Gerber es irónico, crítico y valientemente ácido: analiza y disecciona con valentía la realidad de los setenta no dejando títere con cabeza. Mientras, Lucas -que es fan de la obra original- debe dejar el desarrollo del film a una guionista (la por otra parte genial Gloria Katz, autora de los guiones de Indiana Jones y el templo maldito o American Graffiti) incapaz de comprender el material original. Esto da como resultado un film que a ratos no sabe a qué público está dirigido, si a adultos o a niños, y cuya seña de identidad se pierde entre bobadas y tetas de pato.

Alejados de los ochenta, se experimenta un receso en las producciones de superhéroes tras la bajada de taquilla de Batman vuelve a la mitad con respecto a su predecesora. No obstante, Marvel aprovecha el tirón con telefilms y películas del mercado del vídeo.

Para los noventa y con otro salto en la calidad de los efectos especiales, los estudios están ansiosos por hacerse con franquicias basadas en cómic. Esto coincide con varios factores: el mercado norteamericano se diversifica, surgiendo varias compañías de cómic independientes, desde Image y Valiant -surgidas de antiguos artistas de Marvel- a Dark Horse, que da total libertad creativa y propiedad de los personajes. Y otro factor muy importante: los noventa saludan a Marvel con una crisis brutal que la lleva a la bancarrota. Lo cual tratan de solucionar en parte con una decisión fatal: vende los derechos cinematográficos de sus personajes más punteros, los mutantes y Spiderman. Irónicamente, a la vez crea una división especial para llevar al cine sus propios personajes: Marvel Films (1993).

A finales de los noventa el panorama de las adaptaciones cinematográficas de cómics era desigual: por un lado el público y los productores parecían perder interés en los personajes 


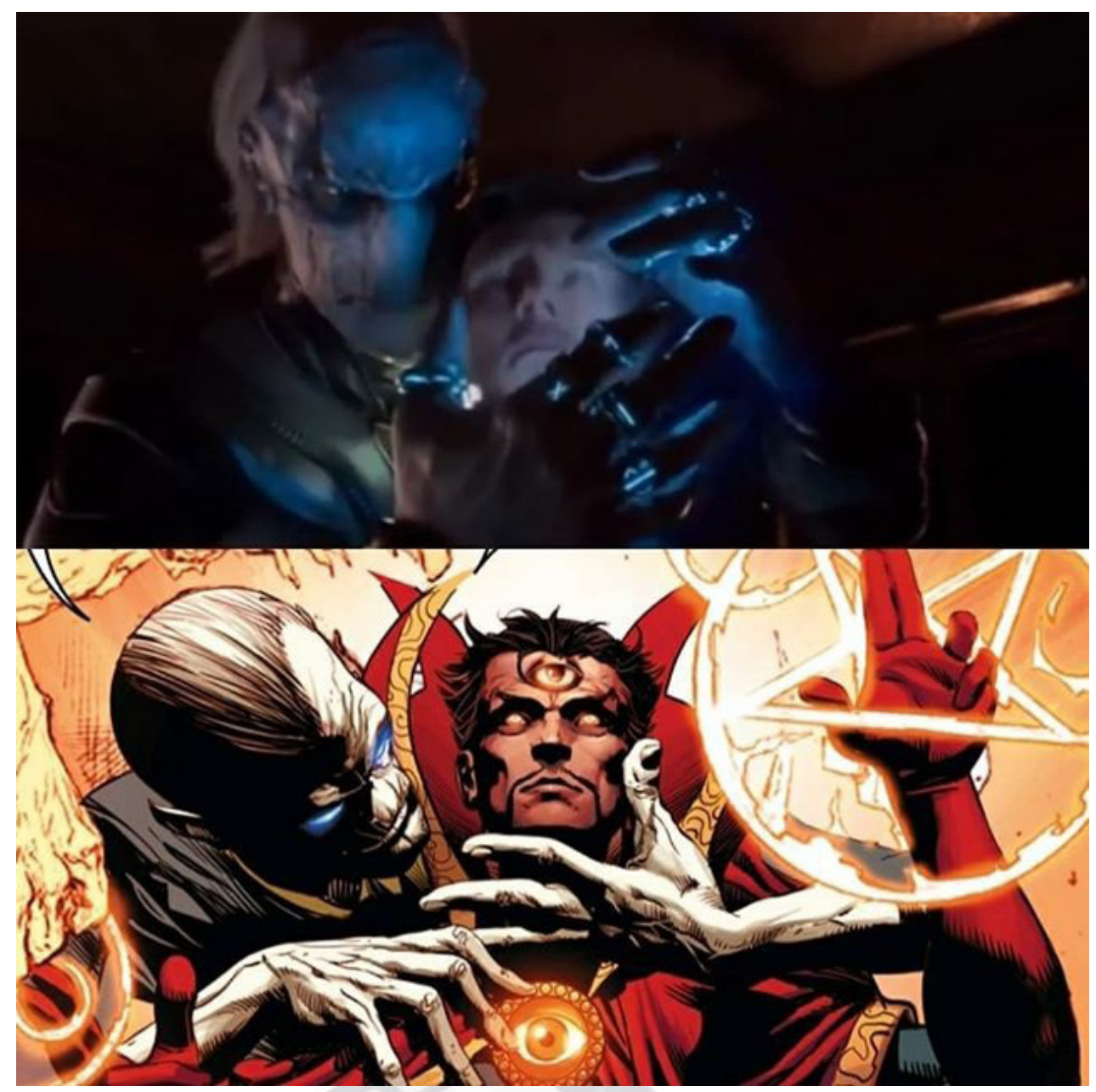

Fotograma de Vengadores: Infinity War y viñeta de cómic Infinity

de DC, mientras que Marvel había conseguido un éxito sin precedentes con Blade (1998), un cazador de vampiros que no parecía provenir del medio. Mientras tanto, en Europa y en Estados Unidos comienzan a surgir adaptaciones de tebeos, alentados quizá por los avances en efectos especiales, en especial el CGI. Y los estudios en busca de nuevas ideas adaptan todo tipo de cómics de distinta temática, desde lo indie a las compañías independientes. El medio, habiendo demostrado ya con creces un alto nivel de madurez, dota a Hollywood de historias alejadas ya del maniqueísmo propio de los héroes Marvel o DC: historias como Camino a la perdición, American Splendor o Ghost World, entre otras muchas.

Es en los años dos mil cuando se produce el cambio de paradigma: los estudios cinematográficos descubren que no solo es más sencillo adaptar una historia de otro medio, sino que es más lucrativo puesto que el trabajo de mercadotecnia ya está hecho. Para aquel entonces el cómic tiene más de ochenta años de historia y una cantidad tal de contenido muy valioso para los productores de cine. Si algo funciona en papel funciona para el público mainstream, como es el caso de Avengers: Infinity War que adapta principalmente los cómics de Marvel guionizados por Jim Starlin y dibujados por George Pérez, y que en los noventa fueron de los más vendidos.

Mundo aparte es el mercado asiático, con una tradición mucho más orgánica entre cine y cómic. Fijándonos solo en el mercado japonés, donde se respetan más los derechos de 


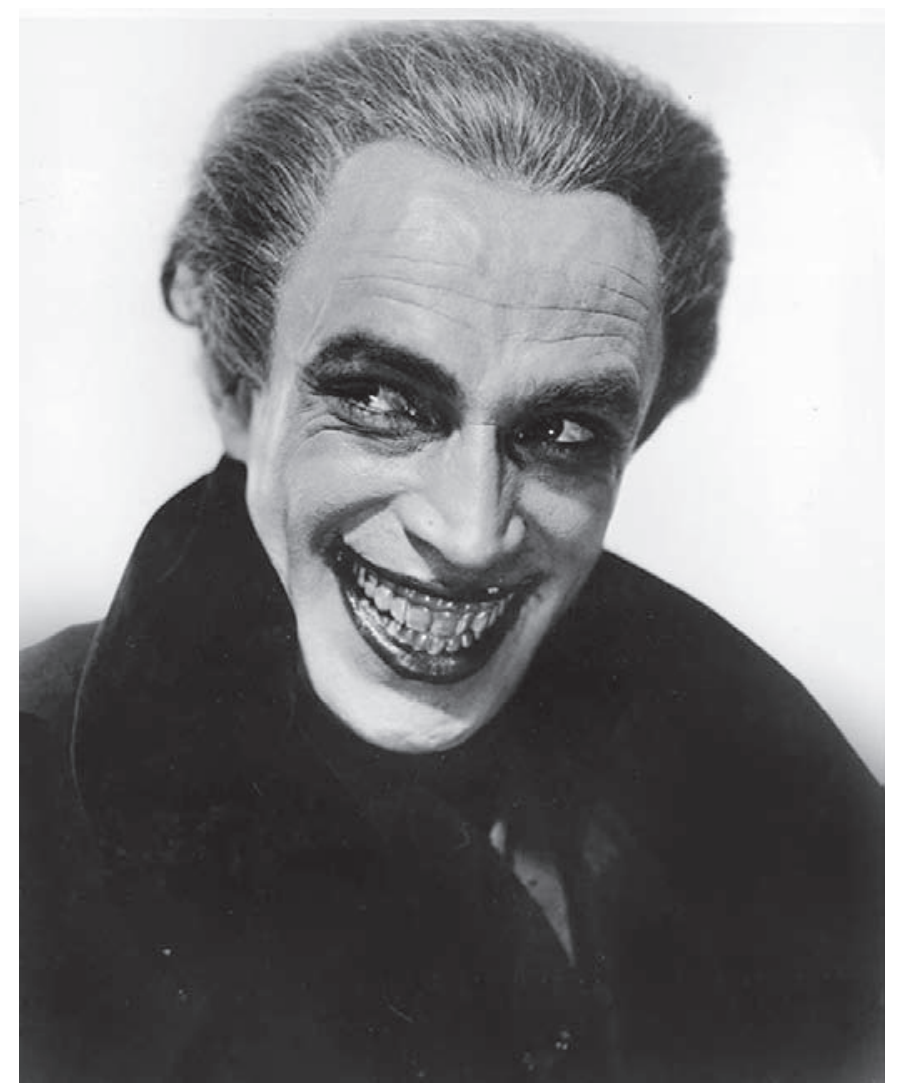

Conrad Veidt como El hombre que ríe (1928)

autor si lo comparamos con la experiencia norteamericana, tenemos el ejemplo de Osamu Tezuka, mangaka cuyas influencias están en la propia Disney y que llegados los años sesenta funda su propia compañía de animación para producir películas y series basadas en sus obras, como Astroboy o Kimba el León Blanco (1950), que por cierto inspiró a Disney a la hora de crear El Rey León (1993). Del cómic, a la serie de animación, al cine. La productora del Dios del Manga fue la primera de una industria que en Japón mueve millones de yenes.

En Europa, cuyo mayor representante sería ante todo Francia (sin olvidarnos de España e Italia), se suben a la ola de adaptaciones alejándose del modelo norteamericano. Aquí se trata de ser fiel a la obra adaptada más que crear un producto paralelo a la misma. Entre 1967 y 2018, se realizan hasta doce títulos de Astérix, creado por Goscinny y Uderzo, primero en dibujos animados para más tarde atreverse con unas muy dignas adaptaciones en live action y finalmente en animación 3D. En el caso de Tintín de Hergé, personaje mucho más longevo pero no tantas veces adaptado, hay apenas siete producciones cinematográficas. Un visionado de cualquiera de estas obras pone de manifiesto lo dicho: el cuidado con el que los cineastas franceses se aproximan a las obras originales.

En España, un país con una gran tradición tebeística y cinematográfica, la relación entre las dos disciplinas es más pobre de lo que cabría esperar. Tan solo en los últimos años se ha visto aumentada la producción cinematográfica de personajes de tebeo, y como hemos dicho ya alentados por el éxito en Estados Unidos de este tipo de cine. Es curioso que en los buenos tiempos del tebeo español, capitaneados por Bruguera, apenas haya películas basadas en su catálogo de personajes. Podemos contar tan solo una, Las aventuras de Zipi y Zape (1981), que aunque se mantiene fiel a la obra de Escobar es un producto más 


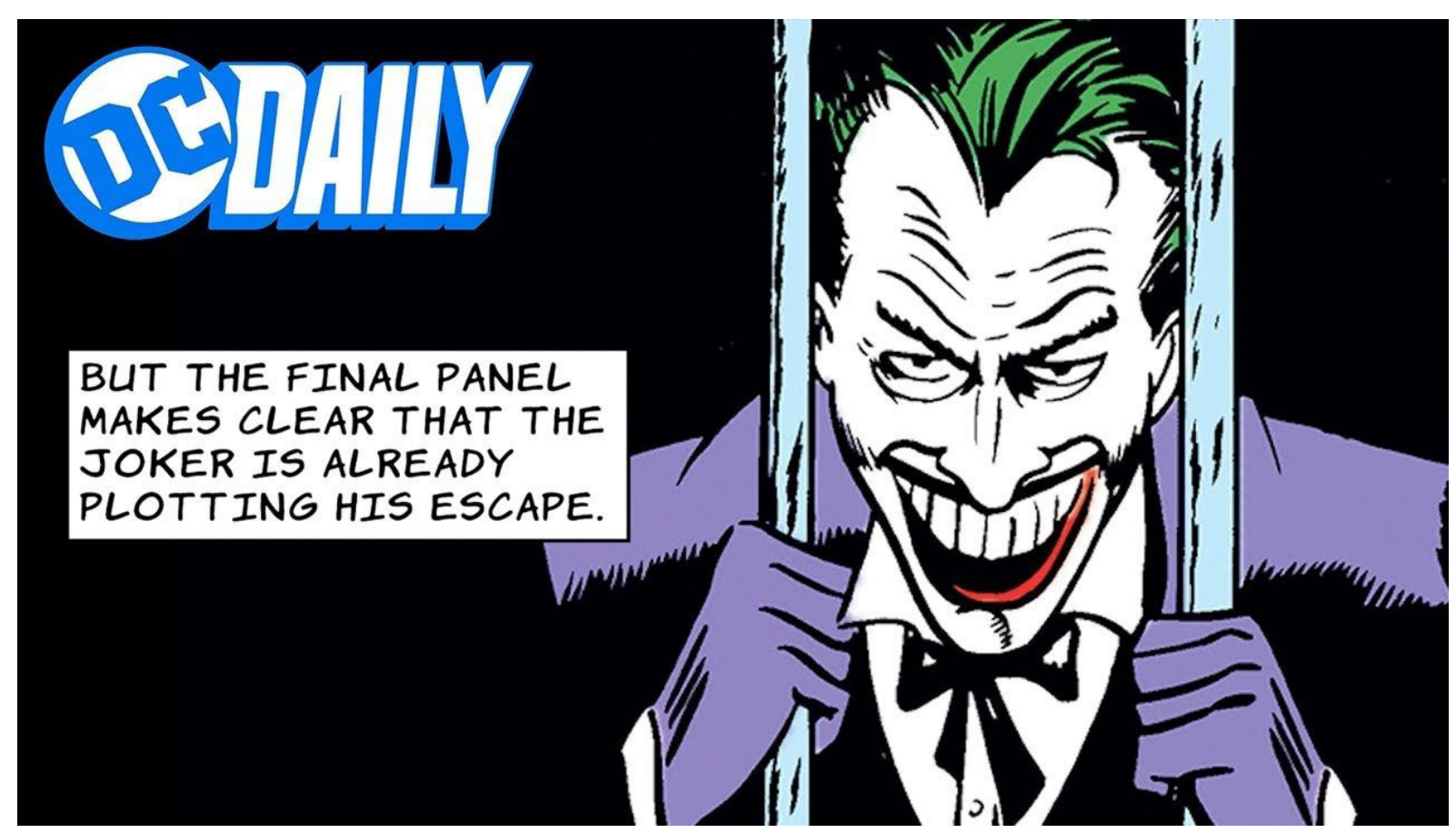

El Joker en su primera aparición (1940)

dirigido a explotar la moda de los grupos infantiles. Pasarían más de veinte años, en 2013, hasta volver a ver a estos traviesos hermanos primero en Zipi y Zape y el club de la canica y después en 2016 con Zipi y Zape y la isla del capitán; ambos productos modernizados tanto que tienen más que ver con Harry Potter o Los Goonies que con sus homólogos creados en 1948. Pero si hay un tebeo español que goza aún a día de hoy de buena salud editorial, ese es Mortadelo y Filemón. Por ello existen hasta cuatro incursiones en el cine de la creación de lbáñez, todas muy dignas y fieles pero a la vez muy dispares debido a la visión distinta de dos directores como Javier Fesser y Miguel Bardem, que son los últimos en aproximarse a estos personajes. Los dos últimos ejemplos de adaptaciones de personajes de Bruguera los tenemos en Anacleto, agente secreto del genial Vázquez y Superlópez del insigne Jan. Tanto una como otra parten de la obra original para contar algo nuevo, siendo quizá el caso de la obra de Jan la que se mantiene más fiel argumentalmente.

Por fijarnos en otras creaciones de España, tenemos a principios de los dos mil el proyecto de adaptar Capitán Trueno a la gran pantalla, epopeya que finalmente llega a buen puerto en el año 2016 después de pasar por las manos de directores como Juanma Bajo Ulloa o Juan Piquer Simón hasta ser adaptado con estrepitoso fracaso por Antonio Hernández, que emplea los personajes creados por Víctor Mora y Miguel Ambrosio Ambrós.

Poco más cabe añadir en cuanto a las adaptaciones en España: poseemos un gran legado, pero muy pocas obras adaptadas o al menos con éxito de crítica y público, aunque en los últimos años la preeminencia de canales de televisión bajo demanda hacen posibles nuevos productos, sobre todo en forma de serie.

Cuando en los noventa Marvel sale a bolsa, era vista como una «Mini-Disney en términos de propiedad intelectual». En 2009, Disney adquiere Marvel Comics. Ya en 2008 su división de cine, Marvel Studios, había iniciado un ambicioso plan de universo cinematográfico compartido: el Ilamado Marvel Cinematic Universe. Cuenta Bob lger en su biografía una 
curiosa conversación con Steve Jobs acerca de Marvel Comics. En un momento dado Jobs le pregunta si es el próximo Pixar. Marvel era mucho más que Pixar, con más años de antigüedad y con una ingente cantidad de personajes creados en sus páginas. Disney dispone hoy en día de una granja de ideas donde empezar a cocinar sus próximos éxitos en salas.

En cuanto a DC/Warner, en 2000 se fusiona con AOL, una empresa de servicio de Internet, y en 2015 es comprada por Verizon. El entramado del que DC forma parte es aún más complicado que el de Marvel/Disney. Ambas compañías comparten sin embargo esa ingente cantidad de propiedades intelectuales de las que sacar nuevos productos más allá del cómic.

Los gigantescos avances en CGl dados desde los años noventa han facilitado enormemente el creernos no solo que un hombre pueda volar sino además columpiarse por Nueva York usando telas de araña, llevar una armadura robótica o tener garras en los antebrazos (aunque sea anatómicamente imposible), entre muchas otras cosas. El increíble presupuesto que los estudios Marvel dedican a sus efectos especiales (sin olvidar afortunadamente el cariño por sus historias) ha hecho posibles grandes epopeyas como Vengadores: Infinity War, basada en el cómic del mismo nombre de donde recoge parte del argumento e incluso traslada directamente a viñetas. Otro caso distinto es su continuación, Vengadores: Endgame, que crea de cero una historia que bien podríamos haber visto publicada por Marvel. Es esta compañía la que ha marcado el ritmo haciendo lo que ha hecho durante años en cómic: crear su propio universo cinematográfico compartido (aunque hay que decir que no es la primera compañía que lo hace, ese honor lo tiene la Toho y su universo de monstruos cuyo rey es Godzilla).

Las demás compañías han ido por detrás tratando de imitar su modelo. En el caso de DC/Warner, una lástima ya que posee tanto contenido para adaptar como su competidora directa y, además, posee el cien por cien de sus activos; al contrario que Marvel, que aún arrastra las consecuencias de haber vendido los derechos de Spiderman.

A día de hoy se continúan creando cómics excelentes, de muchas temáticas y géneros. Los estudios, viendo el éxito cosechado en pantalla y la diversidad del medio, están atentos al que pueda ser el próximo bombazo tanto en los medios on demand, series de TV y por supuesto para el cine. En el 2018 y en Estados Unidos, se superaron los más de ochenta millones de ejemplares vendidos en cuanto a cómic de superhéroes, hablando de las ventas desde su distribuidora oficial Diamond. Se dice que se ha superado el crack de los noventa. Estas cifras, aunque excelentes, no tienen comparación con las de aquella época en la que tan solo en el mes de abril de 1993 se vendieron más de la mitad de esa cifra. La mayor diferencia es que tanto DC/Warner/AOL como Marvel/Disney ven a día de hoy a su sección editorial como granja de ideas, fuente de inspiración para sus proyectos audiovisuales. Confiemos, pues, que los grandes estudios propiedad de esos gigantescos conglomerados, los cuales miran más por el beneficio económico que por la creación cultural, deleguen sus propiedades intelectuales en artistas que amen ambos medios y que respeten no solo las historias de papel sino además a sus creadores, que han sido y serán siempre los pioneros. Aunque sin duda el cómic sufrirá en los próximos años las transformaciones a las que está sujeto desde su creación, la forma de distribuirse y su medio, volviéndose más digital aún, le quedan muchos más años de vida, maravillando a generaciones venideras de lectores que en un futuro podrán disfrutar de nuevas historias como espectadores o creadores en ese medio amigo que es el cine. 